\title{
Investigation of Heat Transfer Augmentation from U-Longitudinal Finned Tube Heat Exchanger
}

\author{
QasimSaleh Mahdi ${ }^{1, *}$, Sahar A. Fattah Abbood ${ }^{1}$, Firas A. Abbas ${ }^{2}$ \\ ${ }^{1}$ Department of Mechanical Engineering, College of Engineering, Al-Mustansirya University, Iraq \\ ${ }^{2}$ Ministry of oil, Gas Filling Company, Iraq
}

Copyright (C) 2015 Horizon Research Publishing All rights reserved.

\begin{abstract}
In the present paper an experimental investigations is carried out to evaluate the enhancement of heat transfer from U-longitudinal finned tube heat exchanger with nanofluids. Laboratory experimental test rig was designed and built up to carried out the experiments. Four U-longitudinal fins are manufactured from $1 \mathrm{~mm}$ copper sheet with $100 \mathrm{~cm}$ long and $3.8 \mathrm{~cm}$ height. Fins are welded with straight copper tube of $100 \mathrm{~cm}$ length, $2.2 \mathrm{~cm}$ inner diameter, and $2.39 \mathrm{~cm}$ outer diameter. The straight tube with fins is fixed inside an insulated galvanized tube with $15 \mathrm{~cm}$ inner diameter. Two types of nanoparticles $\left(\mathrm{Al}_{2} \mathrm{O}_{3}\right.$ and $\left.\mathrm{TiO}_{2}\right)$ having $(<80 \mathrm{~nm}$ and 10 to $25 \mathrm{~nm})$ diameter respectively. Nanoparticles mixing in de-ionized water with $(0.2 \%, 0.4 \%$, $0.6 \%$, and $0.8 \%$ ) volume concentration. The flow through finned tube was studied at Reynolds number ranging from (270 to 1900). Air with turbulent flow is used as a cooling medium passes through the annuli. Results show that the thermal conductivity and heat transfer coefficient are affected more when using alumina-nanofluid. There is an optimum concentration for nanofluids in which more enhancements available. The optimum concentration is $0.6 \%$. The comparison between present results and references showed good agreement.
\end{abstract}

\section{Keywords Heat Exchanger, Finned Tube, Nanofluids}

\section{Introduction}

Finned tube heat exchangers have been used to exchange heat between gases and liquids, which are single or two phases. The performance of the finned tube heat exchanger is limited by the air side heat transfer resistance. This is because the air side heat transfer coefficient is significantly lower than the liquid side heat transfer coefficient [1].Longitudinal fins have proven to be most efficient kinds of fins in many applications. Longitudinal fins are generally used in condensing applications and for various fluids in double pipe and multi-tube heat exchanges, fired heaters, gas coolers and tank heaters [2].Modern technology for heat transfer enhancement is called nanotechnology. This has enabled the production of nanoparticles with average particle size below 100nm. Nanoparticles have thermal properties superior to those of bulk materials of the same composition. Nanofluid is a new class of fluid engineered by dispersing nanometer sized structures in base fluid as water to enhance its thermal conductivity [3]. Taborek[4] updated sketchy methods for double pipe heat exchangers especially for longitudinal finned tubes. Areas and conditions for the most useful applications were outlined. Calculation methods are presented for plain double pipe units, as well as finned tube units, with a new development in the important transition region with cut and twisted turbulence promoters. Equations for the mean temperature difference for units with flow in series-parallel were given.

Yu et al. [5] studied the heat transfer characteristics in the entrance and fully developed regions of tubes with internal wave-like longitudinal fins. Their experiment consists test tube having a double pipe structure, with the inner tube as an insertion. The wave-like fins were in the annulus and span its full width. They conducted two cases for this work, one with the inner tube blocked (no air flowing through it) and the other with the inner tube unblocked. The outer tube was electrically heated. The range of Reynold's number was varied from $9 \times 10^{\wedge} 2$ to $3.5 \times 10^{\wedge} 3$. Results showed that the wave-like fins enhance heat transfer significantly . $\mathrm{Yu}$ and Tao [6] performed study to measure pressure drop and heat transfer characteristics of annular tubes with wave-like longitudinal fins at uniform axial heat input using air as the working fluid on both the entrance and fully developed regions. Five experiments in the annular tubes with waves equal to $4,8,12,16$ and 20 at turbulent flow. It was found that under the three constraints all the wave-like finned tubes can enhance heat transfer and the best wave number was 20 . Lqbal et al. [7] investigated of the optimal longitudinal fins on the outer surface of the inner pipe enclosed within a concentric outer pipe in laminar and fully developed flow at uniform heat flux. The fin-shape was triangular as the initial profile. The results showed that the optimum finshape is dependent on the number of fins, the ration of radii, the number of control points and characteristic length. The enhancement in Nusselt's number was up to $138 \%, 312 \%$ and $263 \%$ for trapezoidal, triangular and parabolic shapes for equivalent diameter while $212 \%, 59 \%$ and $90 \%$ 
respectively for hydraulic diameter. Wen and Ding [8] accomplished an experimental work to study the convective heat transfer of $\gamma-\mathrm{Al}_{2} \mathrm{O}_{3} / \mathrm{de}$-ionized water nanofluid having (27-56) $\mathrm{nm}$ sizes through a copper tube in the laminar flow regime under constant heat flux. Considerable enhancement of convective heat transfer using nanofluid was found especially in the entrance region but decreased in the axial direction. The results also showed that local heat transfer coefficient at axial positions in the entry region was about $41 \%$ and $47 \%$ higher at Reynold's number 1050 and 1600 comparing with water. This enhancement increased with Reynold's number and particle concentration. The possible reasons for this enhancement were discussed and reported that migration of nanoparticles. The main reasons were resulting disturbance of the boundary layer. Heris et al. [9] Preformed experimental investigation of laminar convective heat transfer of $\left(\mathrm{Al}_{2} \mathrm{O}_{3}, \mathrm{CuO}, \mathrm{Cu}\right)$ nanoparticles with $(20,50-60,25) \mathrm{nm}$ diameters respectively. Water was used as a base fluid through a circular tube under constant wall temperature boundary conditions. The heat transfer coefficient for $(0.2-3.0) \%$ volume concentrations of $\left(\mathrm{Al}_{2} \mathrm{O}_{3}, \mathrm{CuO}, \mathrm{Cu}\right)$ nanoparticles and various Peclet numbers were determined. The experimental results emphasized the enhancement of heat transfer. Lai et al [10] Performed experimental study of $\mathrm{Al}_{2} \mathrm{O}_{3}$ / water nanofluid of $(20 \mathrm{~nm})$ size flowing through stainless steel pipe of $(1 \mathrm{~mm})$ size at constant heat flux condition at $(\operatorname{Re}<270)$. They observed enhancement in Nusselts number by $8 \%$ for $1 \%$ volume concentration. Farajollahi et al. [11] Performed an experimental study of $\gamma \mathrm{Al}_{2} \mathrm{O}_{3}$ / water and $\mathrm{TiO}_{2}$ / water nanofluids in a shell and tube heat exchanger under turbulent flow regime. The effect of peclet number, volume concentration and particle type of the heat transfer characteristics was studied. The results concluded that adding of nanoparticles to the base fluid led to the significant enhancement in heat transfer. Different volume fractions were utilized. The comparison of two nanofluid behavior showed that heat transfer characteristics of $\mathrm{TiO}_{2}$ / water nanofluid is better at its optimum concentration. In addition, heat transfer characteristics of $\gamma \mathrm{Al}_{2} \mathrm{O}_{3} /$ water nanofluid has the better heat transfer enhancement at higher nanoparticles concentration. Chandrasekar et al. [12] Conducted fully developed laminar flow convective heat transfer and friction factor characteristics of $\mathrm{\gamma} \mathrm{Al}_{2} \mathrm{O}_{3}$ / water nanofluid through a horizontal tube at constant heat flux with and without the

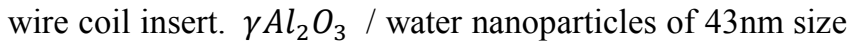
were employed and examined their experiment of $0.1 \%$ volume fraction of nanoparticles. The Nusselts number was increased by $12.24 \%$ at $\mathrm{Re}=2275$ for nanofluid compared with base fluid. Two coil wire inserts from stainless steel having 2 and 3 pitch ratios were fabricated which increased the Nusselts number by $15.91 \%$ and $21.53 \%$ respectively at $\mathrm{Re}=2275$. The results showed that the better heat transfer performance of nanofluid with wire coil insert is attributed to the effects of dispersion. Leong et al. [13] Focused on application of nanofluids in an automotive cooling system.
Ethylene glycol as basefluid and copper particles (0-2) \% volume concentration were used. $3.8 \%$ heat transfer enhancement was achieved with the addition of $2 \%$ copper particles at 6000 and 5000 Reynolds number for air and coolant respectively in their study. The results indicated an increase in thermal performance of the radiator using nanofluid or base fluid with air and coolant Reynolds number. Heat transfer enhancement was observed $42.7 \%$ for pure EG and $45.2 \%$ for EG with $2 \%$ copper nanoparticles when an air Reynolds number was increased from 4000 to 6000 . However, only $0.9 \%$ and $0.4 \%$ enhancement were observed for EG and $2 \%$ copper/EG respectively at Reynolds number increased from 5000 to 7000. $18.7 \%$ reduction in the air frontal area was estimated by adding $2 \%$ copper nanoparticles at $\mathrm{Re}=5000$ and 6000 for air and coolant respectively. This led to an increase in the overall heat transfer coefficient and heat transfer rate by adopting nanofluid. Esmaeilzadeh et al. [14] Investigated hydrodynamics and heat transfer characteristics of $\gamma \mathrm{Al}_{2} \mathrm{O}_{3}$ nanoparticles of $(15 \mathrm{~nm})$ size and distilled water as base fluid inside a circular tube in laminar flow with constant heat flux condition. The effect of different volume concentration on heat transfer enhancement and friction factor was studied showing an increase in heat transfer coefficient with increasing particle volume fraction. Results revealed that the average heat transfer coefficient increases $6.8 \%$ with $0.5 \%$ volume concentration and $19.1 \%$ at $1 \%$ volume concentration comparing with distilled water. Also the change in friction factor was negligible. There are many researches in the literature survey which have been dealt with applications of fins in heat exchangers. It is clear that the literature is very voluminous, but there is a lack off in using nanofluid technique to enhance the U-longitudinal finned tube heat exchanger performance. The main objective of this study is to enhance heat transfer by using several methods such as finned tube with nanofluids. Then new correlations for predicting the Nusselt's number with and without nanofluids are developed. During the present experimental work, the performance will be studied with and without nanofluids by using two kinds of oxide nanoparticles $\left(\mathrm{AL}_{2} \mathrm{O}_{3}\right.$ and $\left.\mathrm{TiO}_{2}\right)$. The present study is carried out at Reynold's number ranging from 270 to 1900 with $(22 \mathrm{~mm})$ inner diameter. Various volume concentrations have been used $(0.2 \%, 0.4 \%, 0.6 \%$, and $0.8 \%$ ) for both types of nanoparticles.

\section{Theoretical Analysis}

Present study consists two fluid flows inside heat exchanger in counter flow arrangement as shown in figure (1). Cold air is forced to flow through annuli and hot de-ionized water is passes through inner tube. Steady state condition, insulated outer surface of heat exchange and no phase changer have been assumed during the analysis of present heat exchanger. Under these conditions the heat dissipation of both sides [15], [16], [17] 


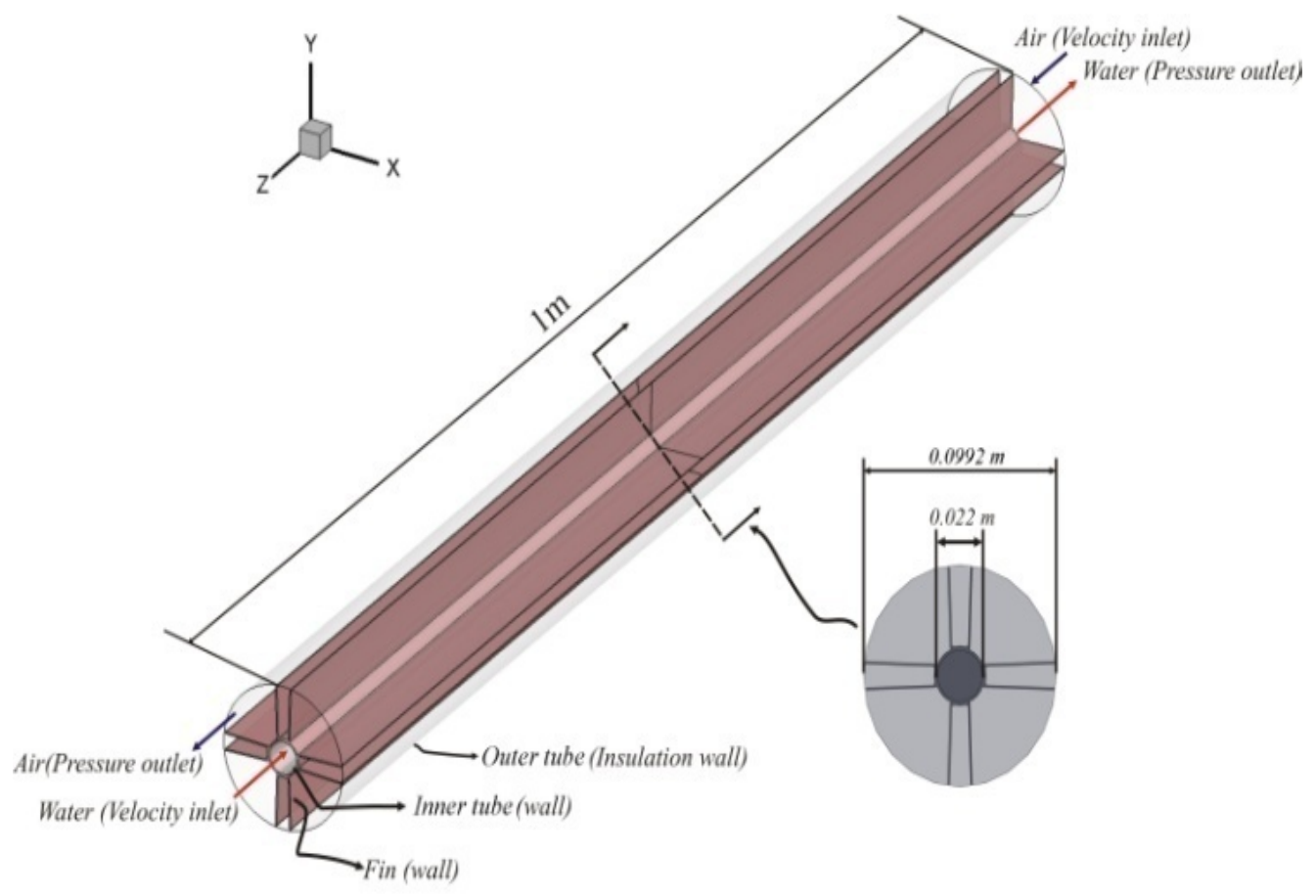

Figure 1. U-longitudinal finned tube heat exchanger

$$
\mathrm{Q}_{\mathrm{c}}=\dot{\mathrm{m}}_{\mathrm{c}} \mathrm{cp}_{\mathrm{c}}\left(\mathrm{T}_{\mathrm{co}}-\mathrm{T}_{\mathrm{ci}}\right) \text { and } \mathrm{Q}_{\mathrm{h}}=\dot{\mathrm{m}}_{\mathrm{h}} \mathrm{cp}_{\mathrm{h}}\left(\mathrm{T}_{\mathrm{hi}}-\mathrm{T}_{\mathrm{ho}}\right)
$$

The heat dissipation during this study is calculated by using the temperature difference on the water side in equation (1)

Heat transfer coefficient of hot side can be calculated as follows:

$$
\mathrm{h}_{\mathrm{i}}=\frac{\mathrm{Q}_{\mathrm{h}}}{\mathrm{A}_{\mathrm{i}}\left(\mathrm{T}_{\mathrm{m}}-\mathrm{T}_{\mathrm{s}}\right)}
$$

Where: $A_{i}=\pi d_{i} 1, \quad T_{m}=\frac{T_{h i}+T_{h o}}{2}$ and $T_{s}=\frac{T_{1}+\cdots+T_{6}}{6}$ Overall heat transfer coefficient can be calculated as:

$$
\mathrm{U}_{\mathrm{i}}=\frac{\mathrm{Q}_{\mathrm{h}}}{\mathrm{A}_{\mathrm{i}} \text { LMTD }}
$$

Where

$$
\begin{gathered}
\mathrm{LMTD}=\frac{\Delta \mathrm{T}_{2}-\Delta \mathrm{T}_{1}}{\ln \left(\frac{\Delta \mathrm{T}_{2}}{\Delta \mathrm{T}_{1}}\right)}, \Delta \mathrm{T}_{1}=\mathrm{T}_{\text {hi }}-\mathrm{T}_{\text {co }}, \Delta \mathrm{T}_{2}=\mathrm{T}_{\text {ho }}- \\
\mathrm{T}_{\mathrm{ci}}
\end{gathered}
$$

The thermal resistance $\frac{\ln \left(\frac{d_{0}}{d_{i}}\right)}{2 \pi k_{t} l}$ can be neglected, annuli heat transfer coefficient can be written as:

$$
\mathrm{h}_{\mathrm{o}}=\frac{1}{\frac{1}{\mathrm{U}_{\mathrm{o}}}-\frac{\left(\mathrm{A}_{\mathrm{u}}+\xi_{\mathrm{t}} \mathrm{A}_{\mathrm{f}}\right)}{\mathrm{h}_{\mathrm{i}} \mathrm{A}_{\mathrm{i}}}}
$$

Where $A_{u}=\left(\pi d_{o} 1-N_{f} l \delta\right), A_{f}=\left(2 H_{f}+\delta\right) N_{f} l$

$$
\begin{gathered}
\xi_{\mathrm{t}}=1-\frac{A_{\mathrm{f}}}{A_{\mathrm{t}}}\left(1-\xi_{\mathrm{f}}\right) \\
\text { And } \mathrm{U}_{\mathrm{o}}=\frac{\mathrm{U}_{\mathrm{i}} \mathrm{A}_{\mathrm{i}}}{\left(\mathrm{A}_{\mathrm{u}}+\xi_{\mathrm{t}} \mathrm{A}_{\mathrm{f}}\right)}
\end{gathered}
$$

Then Nusselt's number for annuli side can be calculates as:

$$
\begin{gathered}
\mathrm{Nu}_{\mathrm{c}}=\frac{\mathrm{h}_{\mathrm{o}} \mathrm{D}_{\mathrm{e}}}{\mathrm{k}_{\mathrm{c}}} \\
\text { where } \quad \mathrm{D}_{\mathrm{e}}=\frac{4 \mathrm{~A}_{\mathrm{c}}}{\mathrm{P}_{\mathrm{h}}} \\
\mathrm{A}_{\mathrm{c}}=\frac{\pi}{4}\left(\mathrm{D}_{\mathrm{i}}^{2}-\mathrm{d}_{\mathrm{o}}^{2}\right)-\left(\delta \mathrm{H}_{\mathrm{f}} \mathrm{N}_{\mathrm{f}}\right), \quad \mathrm{P}_{\mathrm{h}}=\pi \mathrm{d}_{\mathrm{o}} 1+2 \mathrm{H}_{\mathrm{f}} \mathrm{N}_{\mathrm{f}}
\end{gathered}
$$

In this study, the Reynold's number is calculated by the relation:

$$
\begin{gathered}
\operatorname{Re}=\frac{\rho V D_{h u}}{\mu} \\
D_{h u}=d_{i} \quad \text { (laminar flow in the inner tube) } \\
D_{h u}=D_{i}-d_{o} \quad \text { (turbulent flow in smooth annuli) } \\
D_{h u}=\frac{4 A_{c}}{P_{w}}, P_{w}=\pi\left(D_{i}+d_{o}\right)+2 H_{f} N_{f} \quad \text { (turbulent flow } \\
\text { in finned annuli) }
\end{gathered}
$$

The effectiveness is the ratio of the actual heat transfer to the maximum possible amount of heat transfer during the operation of heat exchanger. It can be written as follows:

$$
\varepsilon=\frac{Q_{\text {act }}}{Q_{\max }}
$$

The number of heat transfer units can be defined as:

$$
\mathrm{NTU}=\frac{\mathrm{UA}}{\mathrm{C}_{\min }}
$$

Thermo physical properties $(\mathrm{k}, \mu, \rho$ and $\mathrm{cp}$ ) of nanofluid can be computed from the following relations:

An empirical correlation for thermal conductivity of alumina nanoparticles as follows Buogiorno [18]: 


$$
\mathrm{k}_{\mathrm{nf}}=\mathrm{k}_{\mathrm{bf}}(1+7.47 \varphi)
$$

An empirical formula by Wang et al [19] which lead to two statistical correlations for the viscosity of alumina-nanofluid as follows:

$$
\mu_{\mathrm{nf}}=\mu_{\mathrm{bf}}\left(123 \varphi^{2}+7.3 \varphi+1\right)
$$

The calculation of specific heat is accomplished by the following mixture rule which was recommended by Palm et al [20]:

$$
\mathrm{cp}_{\mathrm{nf}}=(1-\varphi) \mathrm{cp}_{\mathrm{bf}}+\varphi \mathrm{cp}_{\mathrm{p}}
$$

All researchers used mixture rule to calculate density of nanofluids as follow:

$$
(\rho)_{\mathrm{nf}}=(1-\varphi)(\rho)_{\mathrm{bf}}+\varphi(\rho)_{\mathrm{p}}
$$

Table 1. Specifications of nanoparticles [21], [22].

\begin{tabular}{|c|c|c|c|c|}
\hline Type & $\mathrm{D}(\mathrm{nm})$ & $\boldsymbol{\rho}\left(\frac{\boldsymbol{k g}}{\boldsymbol{m}^{\mathbf{3}}}\right)$ & $\mathrm{k}\left(\frac{\boldsymbol{W}}{\boldsymbol{m} \cdot{ }^{\circ} \mathrm{C}}\right)$ & $\mathrm{Cp}\left(\frac{\boldsymbol{J}}{\boldsymbol{k g} \cdot{ }^{\circ} \mathrm{C}}\right)$ \\
\hline $\mathrm{TiO}_{2}$ & $10-25$ & 4230 & 8.9 & 686.2 \\
\hline $\mathrm{Al}_{2} \mathrm{O}_{3}$ & $<80$ & 3970 & 40 & 765 \\
\hline
\end{tabular}

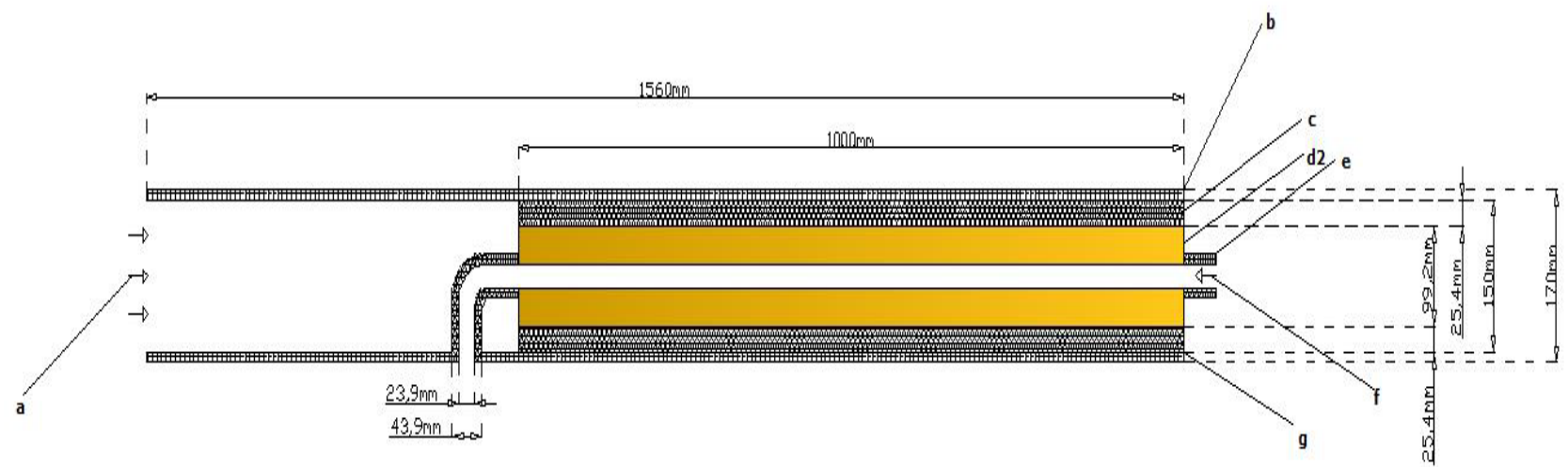

Figure 3. Geometry of present test sections: a. cold air. b. outer insulation (glass wool)for air side. c. inner insulation (arm flux) for air side. d1. smooth tube .d2. finned tube. e. insulation (arm flux) for water side. f. hot water

The test section contains two parts, the first consists insulated tube has been manufactured from galvanized material of $(150 \mathrm{~mm})$ inner diameter, $(1.56 \mathrm{~m})$ length and $(1 \mathrm{~mm})$ thickness. It is insulated from inside by sheet and roll insulation (arm flux) and from outside by glass wool. These insulations have been used to reduce the heat losses to the surrounding. The second part is an internal copper tube without or with $\mathrm{U}$-longitudinal copper fins. The smooth copper tube has $(1 \mathrm{~m})$ long and $(0.022 \mathrm{~m}, 0.0239 \mathrm{~m})$ inner and outer diameter respectively. Pairs of U-shaped fins are manufactured from copper; they are welded to the external surface of tube by silver welding technique to form $\mathrm{U}$-shaped channels having $(1 \mathrm{~m})$ length, $(0.038 \mathrm{~m})$ height, $(1 \mathrm{~mm})$ thickness and $(8.2 \mathrm{~mm})$ distance between every pair and $(9 \mathrm{~mm})$ pitch between each two pairs of fins. A water pump is used for pumping the water in pipes through the water cycle and test section. It has (30liter/minute) volumetric flow rate and centrifugal blower is employed to provide air for the test section through diffuser and fully developed pipe.

\section{Experimental Test Rig}

Figures (2) and (3) show the photograph of test rig and schematic diagram of test section. Test rig consists test section, air and water supply system, measuring devices and supplements. Various kinds of measuring devices have been used such as digital anemometer, temperature recorder, water flow meter, thermocouples and temperature probes.

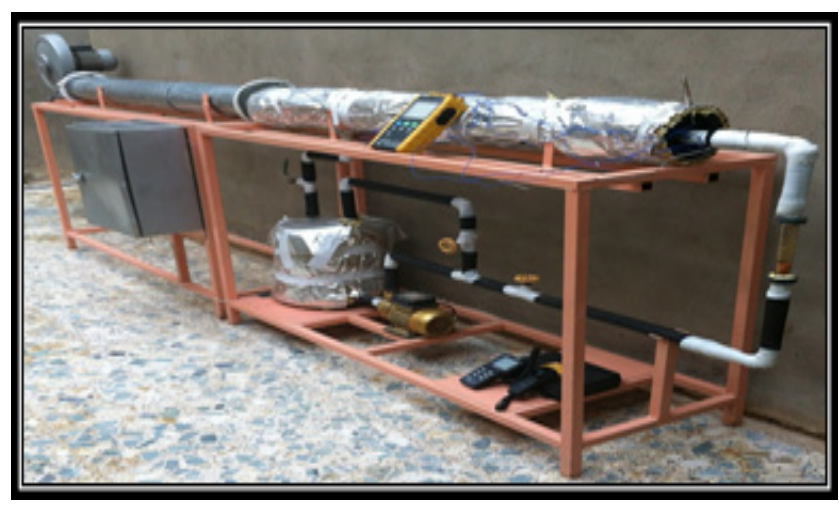

Figure 2. Photograph of test rig.

\section{Results and Discussion}

The performance of the present heat exchanger has been discussed through the following paragraphs. Figure (4) explain the variation of annuli heat transfer coefficient with the air mass flow rate for smooth and U-longitudinal finned tube. Air heat transfer coefficient increased due to turbulence introduced by increasing air velocity. Heat transfer coefficient for finned tube is greater than of smooth tube due to increase surface area by fins. During this study the range of enhancement in air heat transfer coefficient was (1.744 to 2.534$)$.

Figure (5) shows the effect of different water Reynold's number on the inner heat transfer coefficient. It can be seen from these figures that water side heat transfer coefficient increases due to turbulence generated by increasing of water Reynold's number indicating maximum increase of (62.5\%). 


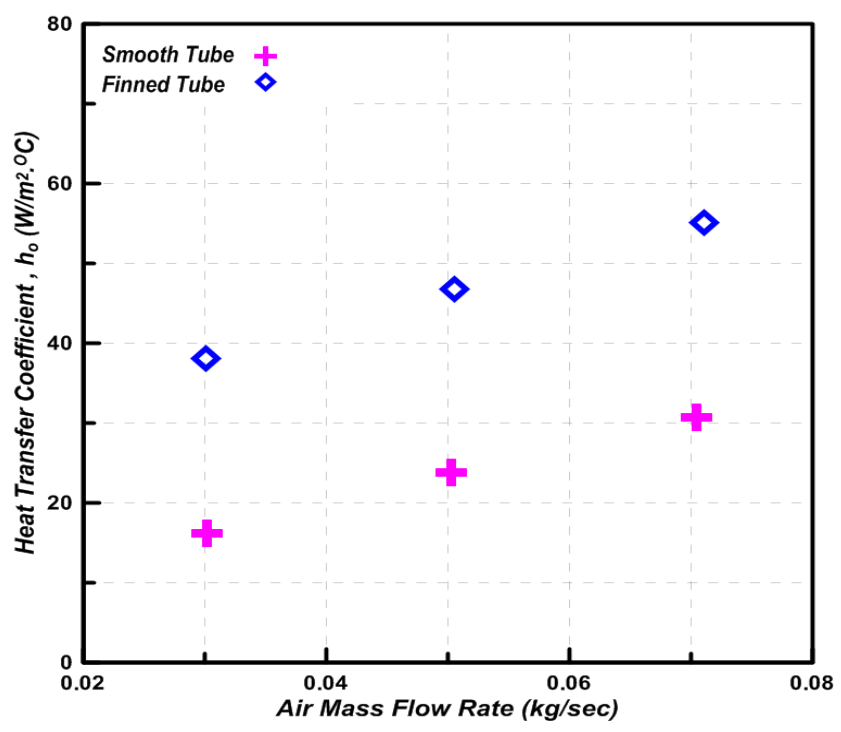

Figure 4. Effect of air mass flow rate on air heat transfer coefficient.

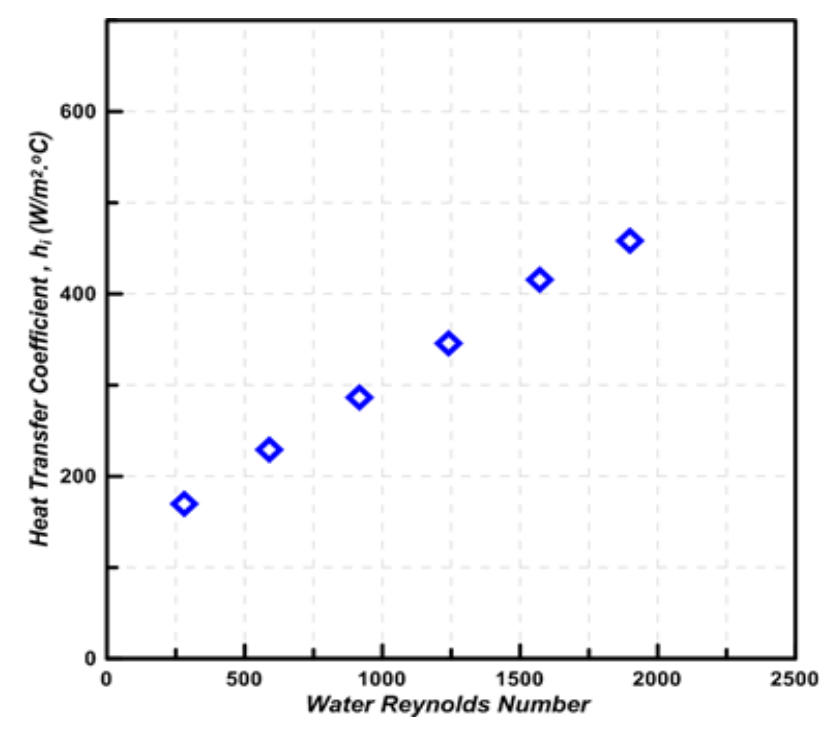

Figure 5. Effect of water Reynold's number on water heat transfer coefficient

Figure (6) show the variation of the air side temperature difference with the air mass flow rate for smooth and $\mathrm{U}-$ longitudinal finned tube. The air temperature difference decreases by $(44 \%)$ as a result of increase air mass flow rate. The air side temperature difference in finned tube is larger by $(65 \%)$ than that of smooth tube due to enhancement by increasing the surface area.

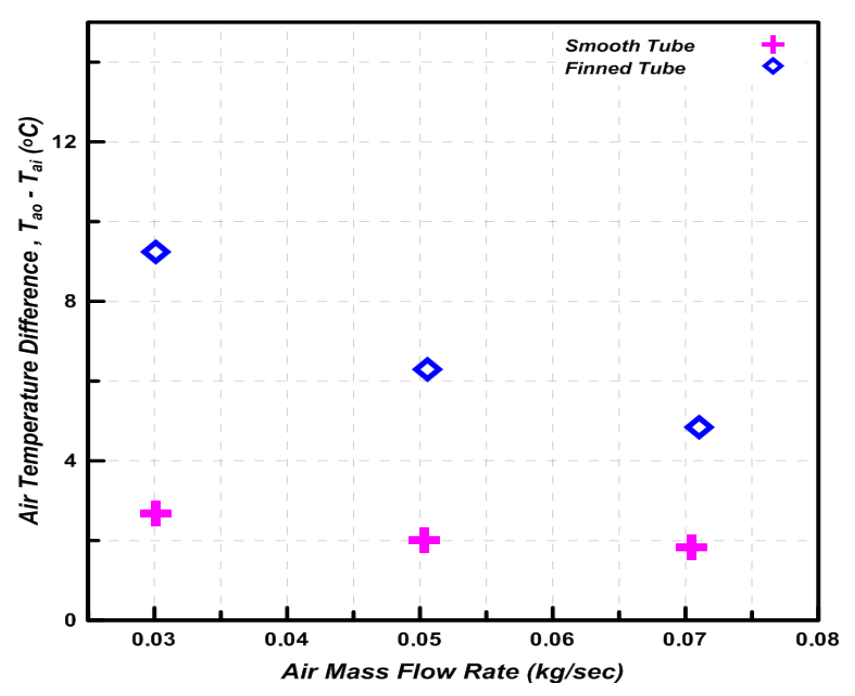

Figure 6. Effect $\mathrm{f}$ air mass flow rate on air temperature difference.

Figures (7) illustrates the variation of the water side temperature difference with the water Reynold's number for smooth and U-longitudinal finned tube. The water side temperature difference tends to decrease $(67 \%)$ by increasing water Reynold's number.

Figures (8) and (9) illustrate the variation of effectiveness with number of transfer units in the present study. Positive relationship can be noted in these figures due to the dependence of the number of transfer units and effectiveness on the overall heat transfer coefficient. Effectiveness of finned tube is greater than that of smooth tube by $(68 \%)$.

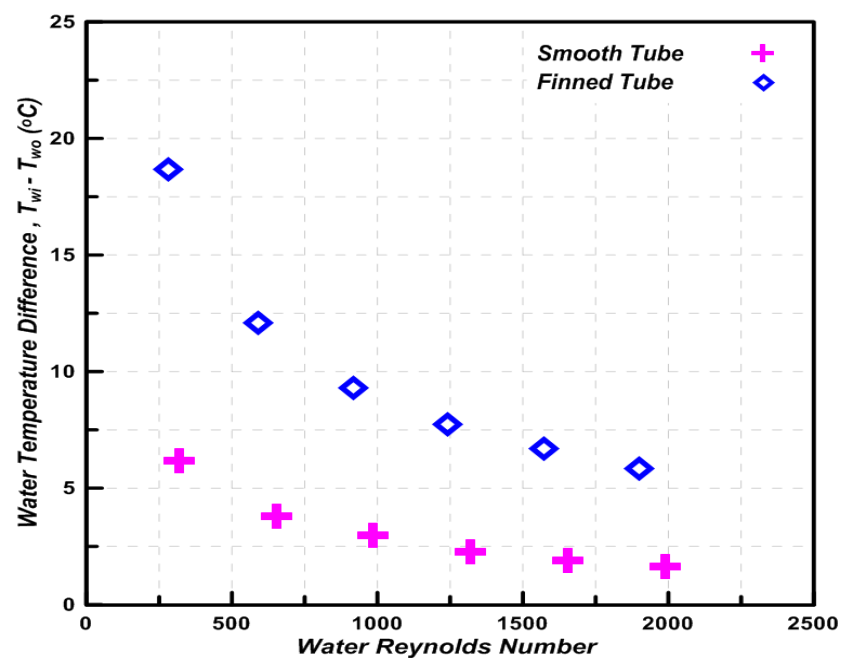

Figure 7. Effect of water Reynold's number on water temperature difference. 


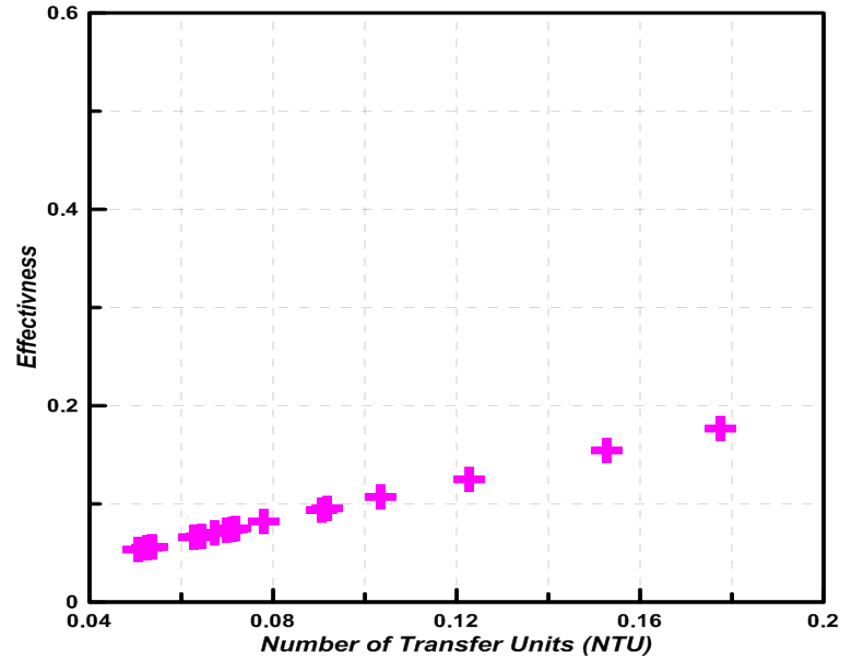

Figure 8. Variation of effectiveness with number of transfer units in smooth tube

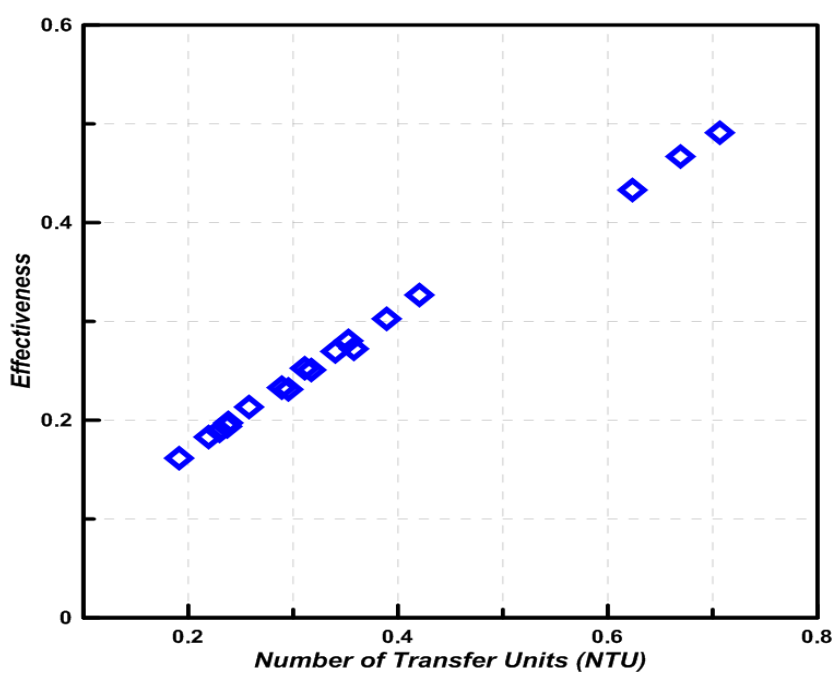

Figure 9. Variation of effectiveness with number of transfer units in finned tube.

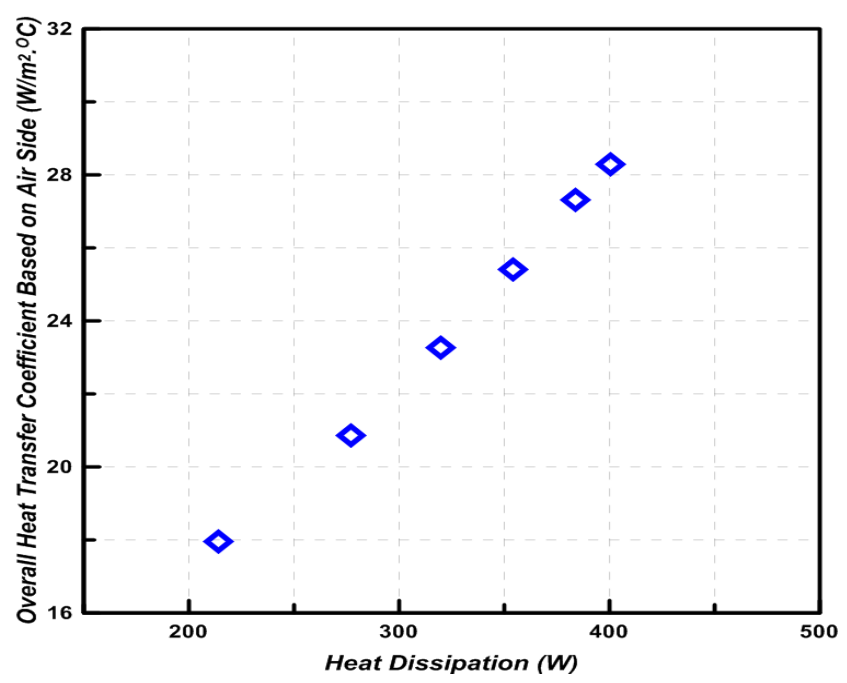

Figure 10. Effect of heat dissipation on $\mathbf{U}_{\mathbf{o}}$ and heat dissipation
Figure (10) illustrate the relation between overall heat transfer coefficient based on air side and heat dissipation calculating from the water side. Heat dissipation increased when the overall heat transfer coefficient increase. Overall heat transfer coefficient represents the overall ability of conductive and convective resistant's to heat transfer and it is commonly applied to observe the behavior in the heat exchanger.

Figure (11) shows the variation of inner tube surface temperature with axial distance ratio at various water Reynold's number. It can be noted from these figures that surface temperature decreases with axial distance ratio due to the counter flow arrangement of the present heat exchanger. Surface temperature increase with increase water Reynold's number by (30\%).

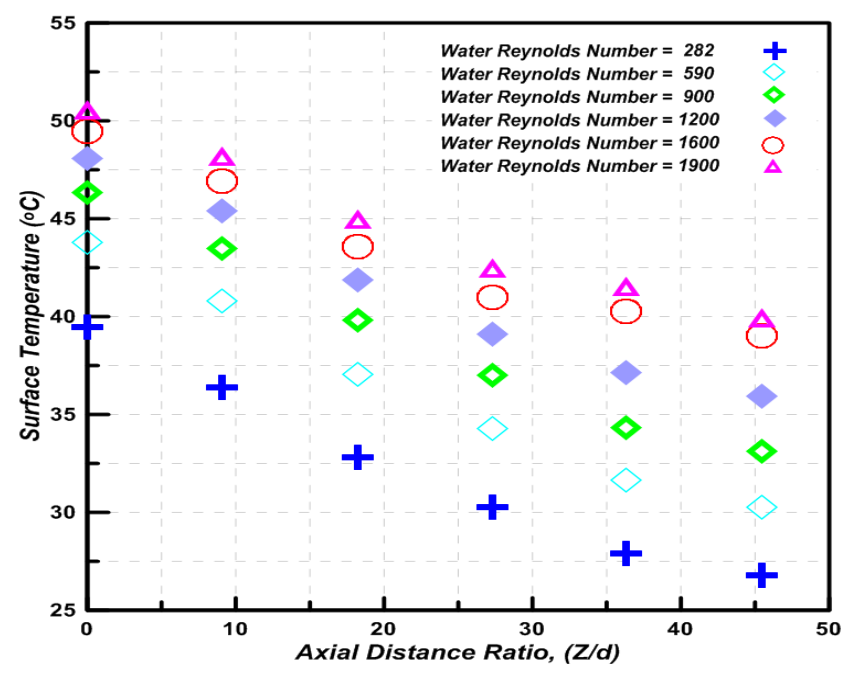

Figure 11. Variation of surface temperature with axial distance ratio.

Performance of U-longitudinal finned tube heat exchanger with nanofluids has been studied to show the effect of both concentration and type of nanoparticles on heat transfer enhancement. Air Reynold's number has been selected as 13000 during nanofluids experiments. The thermal performance of heat exchanger with nanofluids is described in the following paragraphs:

Figures (12) and (13) present the variation of heat transfer coefficient of alumina-nanofluids and titania-nanofluids respectively with different of Reynold's number at different volume concentration of nanoparticles. These figures reveal that the heat transfer coefficient increases by increasing both Reynold's number of Nano fluid and volume concentrations of nanoparticles in base fluid. By increasing volume concentration of nanoparticles, thermal conductivity increases while the thermal boundary layer thickness decreases. This is due to mobility of particles near the wall, migration of them to the center of the tube and reduction of viscosity at the wall region [11]. It is clear that alumina-nanofluid has better enhancement characteristics than titania- nanofluid due to thermal conductivity effect. 


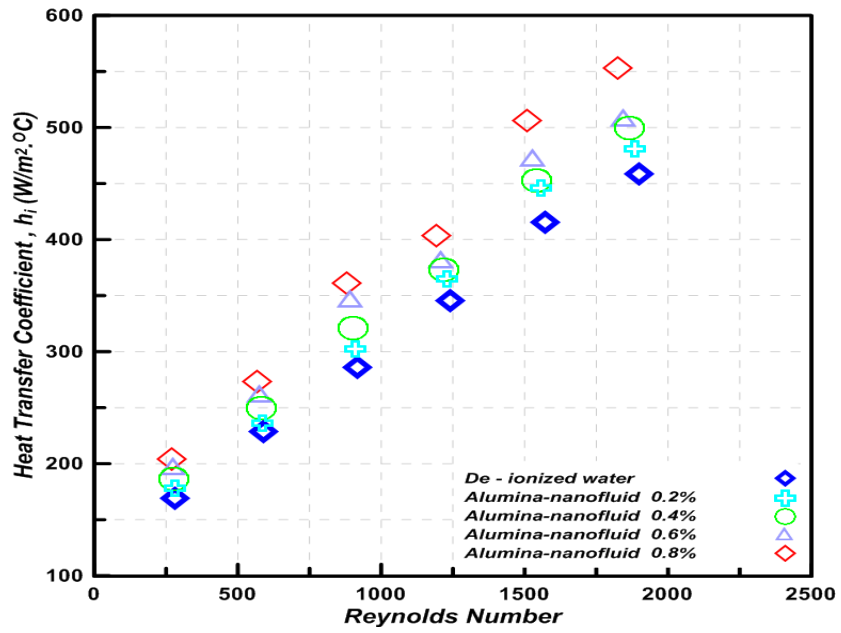

Figure 12. Variation of inner heat transfer coefficient with Re at various volume concentrations for alumina-nanofluid.

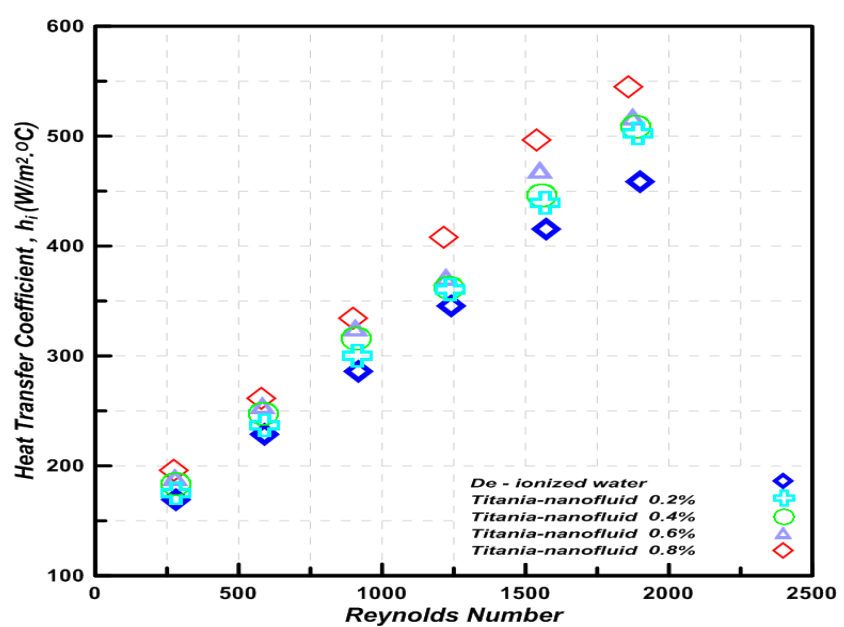

Figure 13. Variation of inner heat transfer coefficient with Re at various volume concentrations for titania-nanofluid

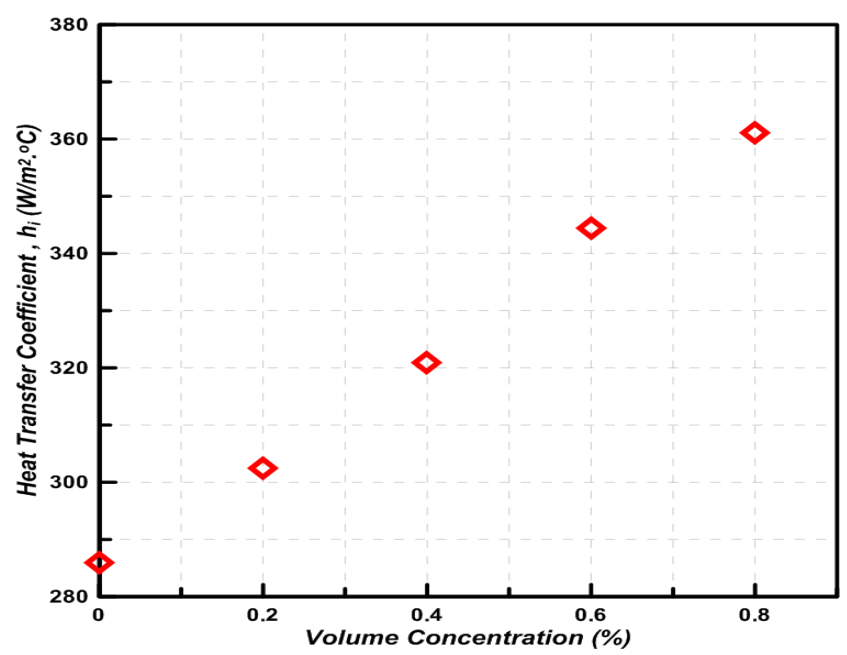

Figure 14. Effect of alumina-nanofluid concentration on $h_{i}$

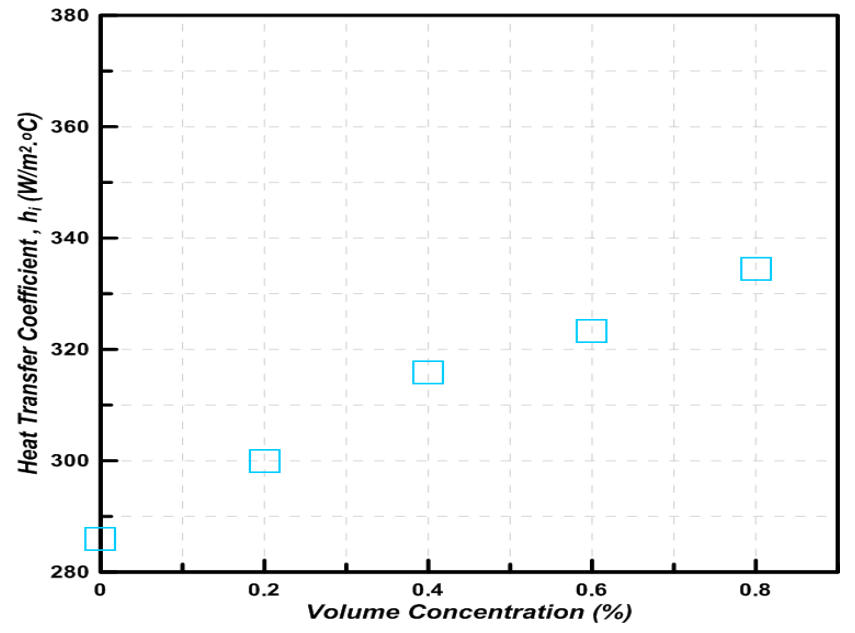

Figure 15. Variation of inner heat transfer coefficient with volume concentrations of titania-nanofluid.

Figures (14) and (15) show the effect of volume concentration on heat transfer coefficient in alumina and titania- nanofluids respectively. The enhancement in $\mathrm{h}_{\mathrm{i}}$ are $21 \%$ and $16.29 \%$ at $0.8 \%$ concentration respectively.

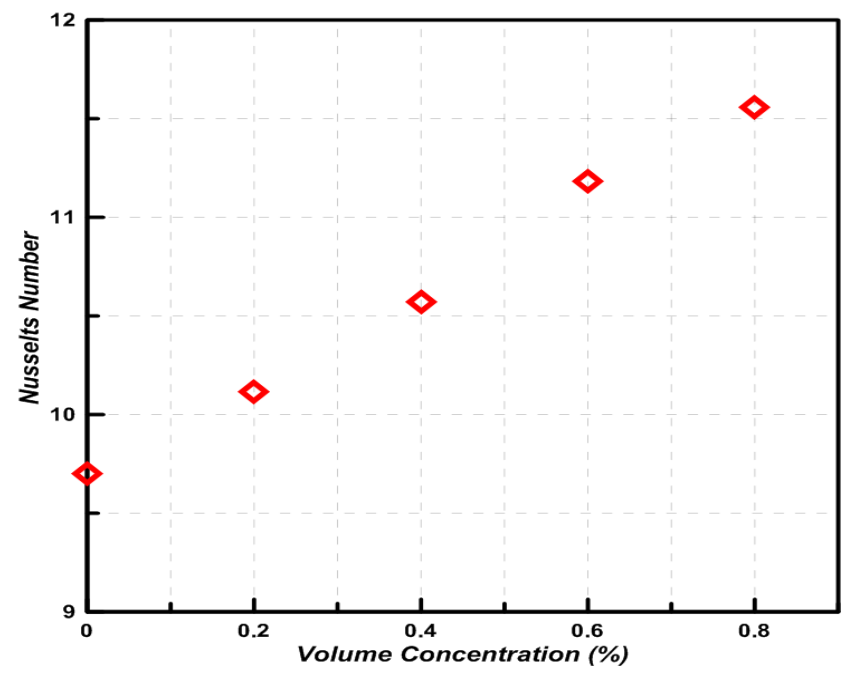

Figure 16. Variation of inner Nusselt's number with volume concentrations of alumina- nanofluid.

Figures (16) and (17) show the effect of volume concentration on the Nusselt's number in alumina-nanofluids and titania-nanofluids respectively. With their figures represents the enhancement of the Nusselt's number in the inner tube for both alumina-nanofluids and titania-nanofluids over basefluid. The maximum enhancement is $(19.15 \%)$ and $(12.39 \%)$ for alumina and titania -nanofluids respectively. 


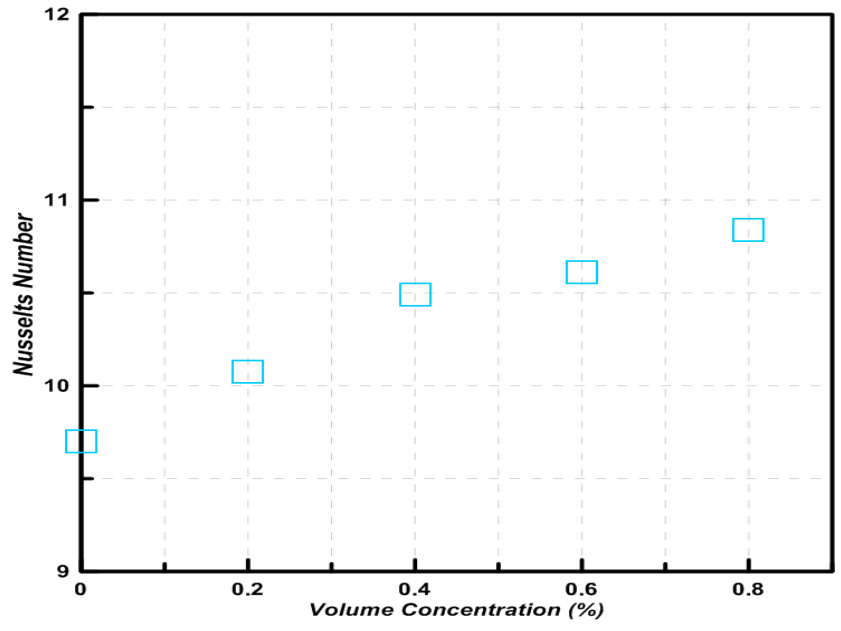

Figure 17. Variation of inner Nusselt's number with volume concentrations of titania-nanofluid

Figures (18) and (19) show the effect of volume concentration on heat dissipation in alumina-nanofluids and titania-nanofluids respectively. These figures show the enhancement of heat dissipation for alumina-nanofluids and titania-nanofluids respectively over basefluid. The maximum enhancement was $(12.3 \%)$.

Figures (20) and (21) represent the effect of volume concentration on overall heat transfer coefficient based on the air side of alumina-nanofluids and titania- nanofluids respectively. Figures show the enhancement of overall heat transfer coefficient . The maximum enhancement is $(15.67 \%)$ and $(14.74 \%)$ for alumina and titania-nanofluids respectively.

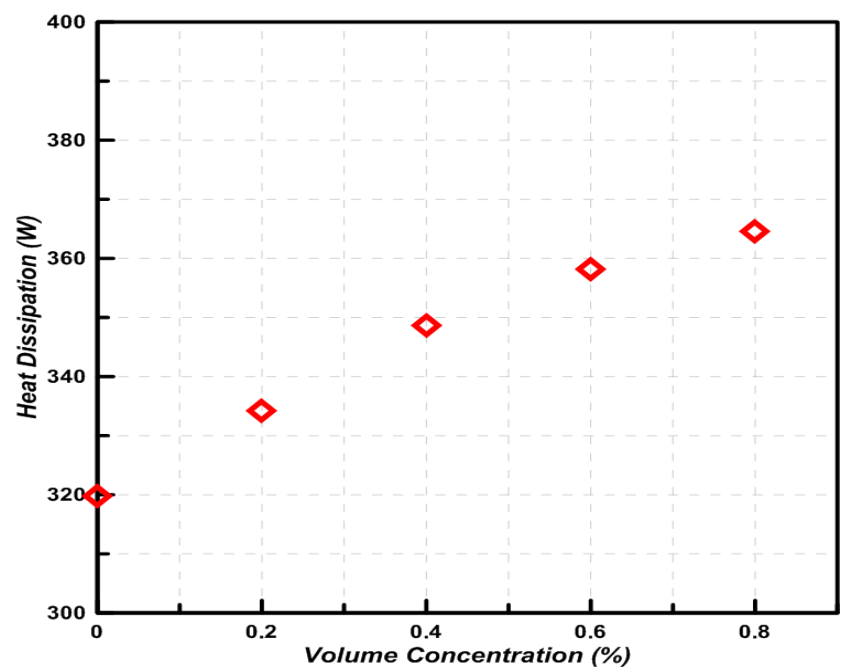

Figure 18. Variation of heat dissipation with volume concentrations of alumina-nanofluid

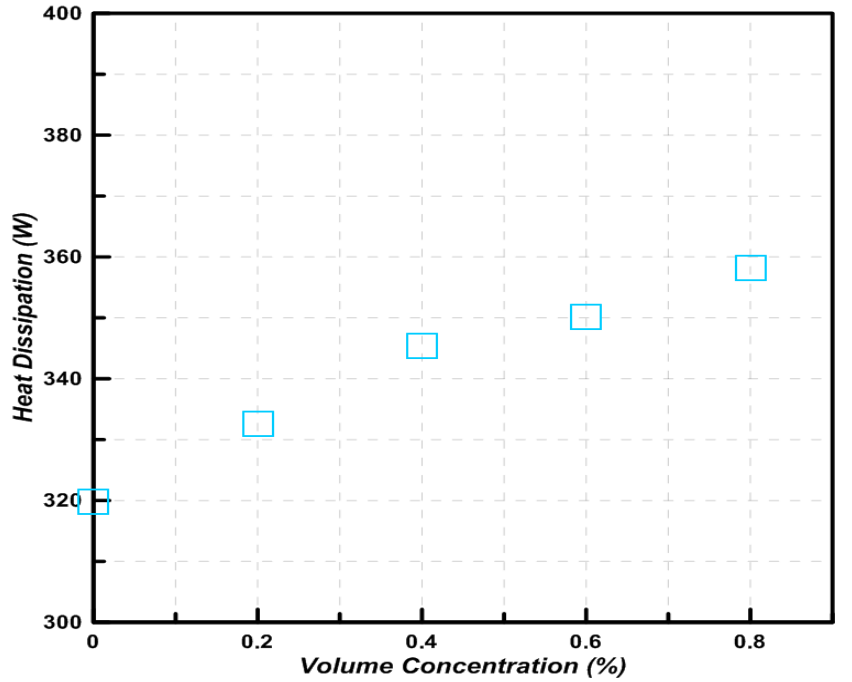

Figure 19. Variation of heat dissipation with volume concentrations of titania-nanofluid.

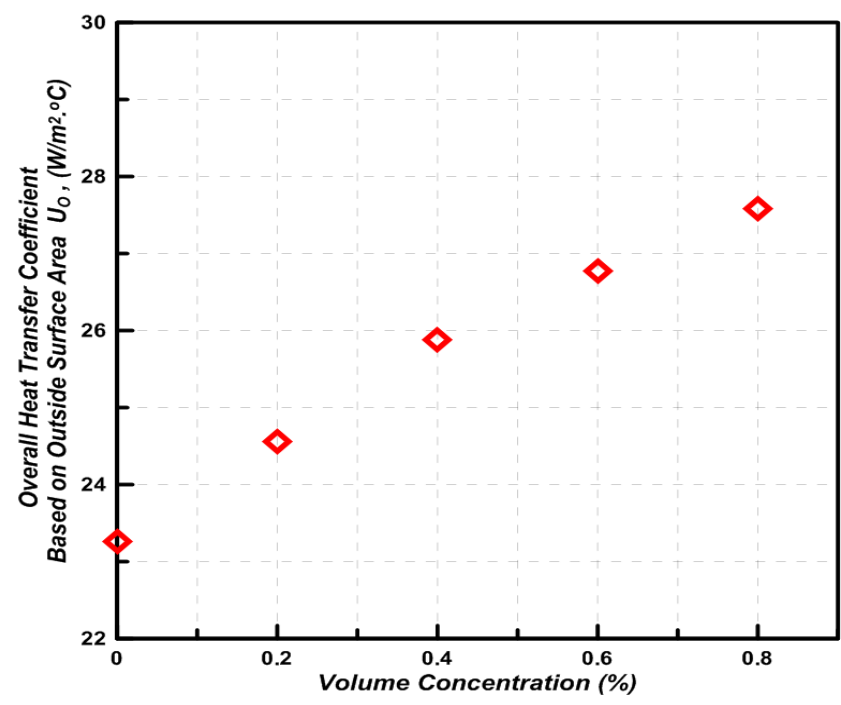

Figure 20. Variation of overall heat transfer coefficient based on air side with volume concentrations of alumina-nanofluid.

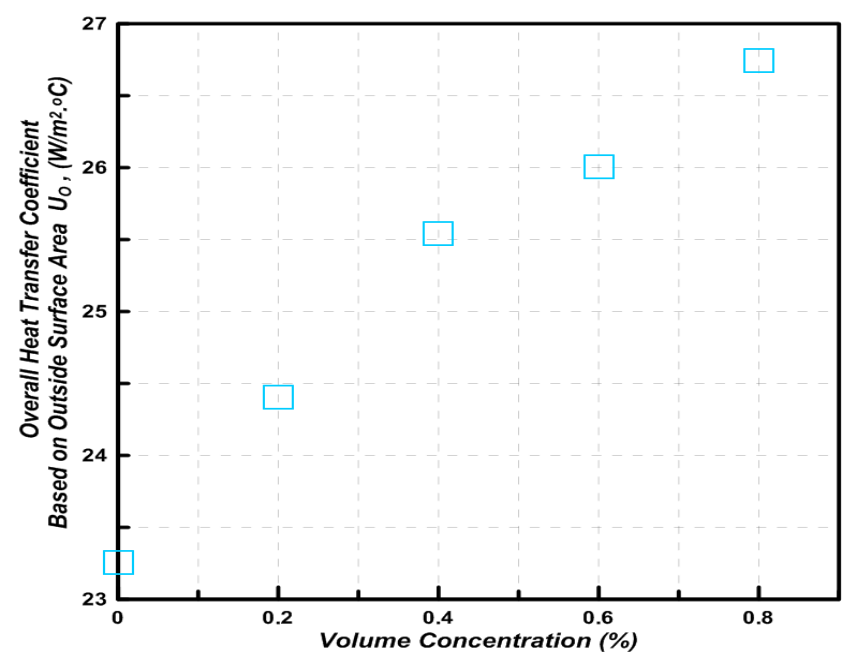

Figure 21. Variation of overall heat transfer coefficient based on air side with volume 


\section{Empirical Correlations}

Empirical correlations of Nusselt's number were developed from the experimental results as shown in the following. This is accomplished by using DGA program and according to algebraic expression of the form $(\boldsymbol{Y}=\boldsymbol{a}$ $X_{1}^{N_{1}} X_{2}^{N_{2}}$

Air side empirical correlation

$$
\mathrm{Nu}_{\mathrm{c}}=0.909 \operatorname{Re}^{0.433} \operatorname{Pr}^{1 / 3}
$$

Above relation are valid for $8000<R e_{c}<18000$

Water side empirical correlation

$$
\mathrm{Nu}_{\mathrm{h}}=0.112(\operatorname{Re} \operatorname{Pr})^{0.562}
$$

Alumina-nanofluid side empirical correlation

$$
\mathrm{Nu}_{\mathrm{nf}}=0.191(\operatorname{Re} \operatorname{Pr})^{0.558}(\varphi)^{0.075}
$$

Titania-nanofluid side empirical correlation

$$
\mathrm{Nu}_{\mathrm{nf}}=0.145(\operatorname{Re} \operatorname{Pr})^{0.576}(\varphi)^{0.055}
$$

Above relations are valid for $270<\mathrm{Re}_{\mathrm{h}}<1900$

Figure (22) shows the comparison between present results and Shah equation [23].

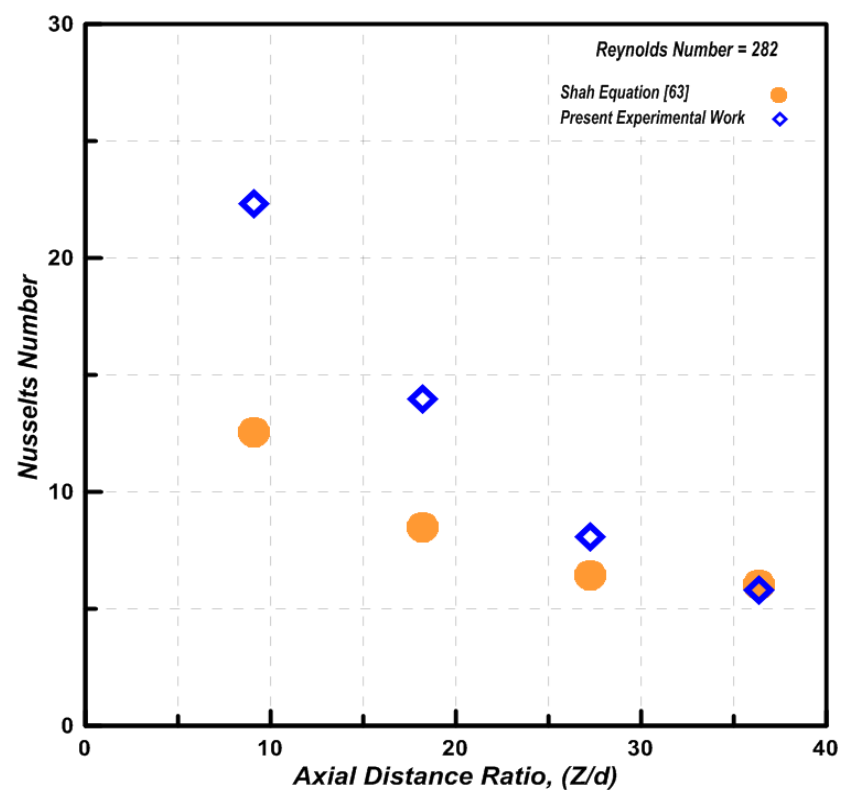

Figure 22. Comparison between experimental work and Shah equation [19].

\section{Conclusions}

The conclusions resulting from present study will be outlined in the following points:

1. The heat transfer augmentation is apparent when adopting fins on outer surface of inner tube in present heat exchanger. This enhancement appears clearly in heat dissipation and air heat transfer coefficient indicating (2.79 to 3.43$)$ and (1.744 to 2.534) times than that of smooth tube respectively.
2. Air side temperature difference is directly proportional with the water Reynold's number and decreased by (44\%) with increasing the air mass flow rate.

3. Water side temperature difference is directly proportional to the air mass flow rate and decreased by $(67 \%)$ with increasing the water Reynold's number.

4. Significant enhancement has been found in heat exchanger effectiveness by adopting fins on outer surface of inner tube.

5. Adding nanoparticles to basefluid causes distinct augmentation in heat transfer coefficient for present heat exchanger. It can be noted that maximum enhancement has been observed as $(21 \%, 16 \%)$ for alumina and titania nanoparticles respectively at $(0.8 \%)$ volume concentration.

\section{Nomenclature}

$\begin{array}{ll}\text { As } & \text { Surface area } \\ \mathrm{C} & \text { Heat capacity } \\ \mathrm{Cp} & \text { Specific heat } \\ \mathrm{D} & \text { Diameter of insulated pipe } \\ \mathrm{De} & \text { Equivalent diameter of annuli } \\ \mathrm{Dhu} & \text { Hydraulic diameter of annuli } \\ \mathrm{D} & \text { Diameter of inner tube } \\ \mathrm{H} & \text { Heat transfer coefficient } \\ \mathrm{H} & \text { Height } \\ \mathrm{K} & \text { Thermal conductivity } \\ \mathrm{L} & \text { Length } \\ \mathrm{m} & \text { Mass flow rate } \\ \mathrm{N} & \text { Number of fins } \\ \mathrm{Nu} & \text { Nusselt's number } \\ \mathrm{Pr} & \text { Prandtl's number } \\ \mathrm{P}_{\mathrm{h}} & \text { Perimeter } \\ \mathrm{Q} & \text { Heat dissipation } \\ \mathrm{Re} & \text { Reynold's number } \\ \mathrm{T} & \text { Temperature } \\ \mathrm{Tci} & \text { Inlet temperature of cold fluid } \\ \mathrm{Tco} & \text { Outlet temperature of cold fluid } \\ \mathrm{Thi} & \text { Inlet temperature of hot fluid } \\ \mathrm{Tho} & \text { Outlet temperature of hot fluid } \\ \mathrm{U} & \text { Overall heat transfer coefficient } \\ \mathrm{V} & \text { Velocity } \\ \mathrm{Z} / \mathrm{d} & \text { Axial distance ratio } \\ & \end{array}$

Greek symbols

$\varepsilon \quad$ Heat exchanger effectiveness

$\delta \quad$ Fin thickness

$\mu \quad$ Dynamic viscosity

$\rho$ Density

$\alpha$ Thermal diffusivity

$\varphi$ Volume concentration percentage . 


\begin{tabular}{ll}
\multicolumn{2}{l}{ Subscripts } \\
Act & Actual \\
Bf & Basefluid \\
C & Cold \\
F & Fin \\
H & Hot \\
i & Inner \\
nf & Nanofluid \\
m & Mean \\
max & Maximum \\
min & Minimum \\
o & Outlet \\
p & Particle \\
s & Surface \\
t & Tube \\
u & Unfinned \\
w & Wetted
\end{tabular}

Abbreviations

DGA Dimensional group analysis.

LMTD Logarithmic mean temperature difference.

NTU Number of transfer units.

\section{REFERENCES}

[1] Jong Min Choi,Yonghan Kim, Mooyeon Lee, Yongchan Kim, "Air Side Heat Transfer Coefficients of Discrete Plate Finned-Tube Heat Exchangers with Large Fin Pitch",Applied Thermal Engineering, Vol.30, pp.174-180, 2010.

[2] Ramesh K. Shah, Dušan P. Sekulic ${ }^{2}$, "Fundamentals of Heat Exchanger Design ",Jon Wiley \& Sons, 2003.

[3] Stephen U. S. Choi, "Nanofluids: A New Field of Scientific Research and Innovative Applications", Heat Transfer Engineering, Vol.29 (5), pp.429-431, 2008.

[4] Taborek Jerry, "Double-Pipe and Multitube Heat Exchangers with Plain and Longitudinal Finned Tubes", HeatTransfer Eng. Vol.18 (2), pp.34-45, 1997.

[5] Yu B., Nie J. H., Wang Q. W., Tao W. Q., "Experimental Study on The Pressure Drop and Heat Transfer Characteristics of Tubes with Internal Wave-like Longitudinal Fins", Heat and Mass Transfer, Vol.35, pp.65-73, 1999 .

[6] Yu B., Tao W. Q., "Pressure Drop and Heat Transfer Characteristics of Turbulent Flow in Annular Tubes with Internal Wave-Like Longitudinal Fins", Heat and Mass Transfer, Vol.40, pp.643-651, 2004.

[7] Iqbal Z., Syed K. S., Ishaq M., "Optimal Fin Shape in Finned Double Pipe with Fully Developed Laminar Flow", Applied Thermal Engineering, Vol.51, pp.1202-1223, 2013.

[8] Wen D., Ding Y.,"Experimental Investigation into Convective Heat Transfer of Nanofluids at the Entrance Region Under Laminar Flow Conditions", International Journal of Heat and Mass Transfer Vol.47, pp.5181-5188, 2004.
[9] Zeinali Heris S., Nasr Esfahany M., Etemad S. Gh., "Heat Transfer Enhancement of Nanofluid Laminar Flow", $14^{\text {th }}$ Annual (International) Mechanical Engineering Conference, 2006.

[10] Lai W.Y., Duculescu B., Phelan, "Proceeding of ASME International Mechanical Engineering Congress and Exposition", Chicago, USA, 2006.

[11] Farajollahi B., Etemad S. Gh., Hojjat M., "Heat Transfer of Nanofluids in A Shell and Tube Heat Exchanger", International Journal of Heat and Mass Transfer, Vol.53, pp.12-17, 2010.

[12] Chandrasekar M., Sureh S., Chandra Bose A., "Experimental Studies on Heat Transfer and Friction Factor Characteristics of $\mathrm{Al}_{2} \mathrm{O}_{3} /$ Water Nanofluid in a Circular Pipe Under Laminar Flow with Wire Coil Inserts", Experimental Thermal and Fluid Science Vol.34, pp.122-130, 2010.

[13] Leong K. Y., Saidur R., Kazi S. N., Mamun A. H., "Performance Investigation of an Automotive Car Radiator Operated with Nanofluids - Based Coolant (Nanofluids Coolant in a Radiator", Applied Thermal Engineering, Vol.30, oo.2685-2692, 2010.

[14] Esmaeilzadeh E., Almohammadi H., Nasiri Vatan Sh., Omran A. N., "Experimental Investigation of Hydrodynamics and Heat Transfer Characteristics of $\gamma$ $\mathrm{Al}_{2} \mathrm{O}_{3} /$ Water Under Laminar Flow Inside a Horizontal Tube", International Journal of Thermal Science, Vol.63, pp.31-37, 2013.

[15] Frank P. Incropera, David P. Dewitt, Theodore L. Bergman, Adrienne's S. Lavine, "Introduction to Heat Transfer", John Wiley \& Sons Inc., 2007.

[16] Sadik Kakac, Hongtan Liu, "Heat Exchangers Selection, Rating and Thermal Design", Second Edition, Dept. of Mech. Eng. Univ. of Miami, Coral Gables, Florida, 2002.

[17] Sahiti N., Durst F., Dewan A., "Heat Transfer Enhancement by Pin Elements", International Journal of Heat and Mass Transfer, Vol.48, pp. (4738-4747), 2005.

[18] Buongiorno, J., "Convective Transport in Nanofluids", Journal of Heat Transfer, pp.128-240, 2006

[19] Wang, X., Xu X. and Choi S. U. S., "Thermal Conductivity of Nanoparticle-fluid Mixture", Journal of Thermo physics and Heat Transfer, Vol.13, pp.474-480, 1999.

[20] Palm S. J., Roy G., Nguyen C. T., "Heat Transfer Enhancement with the Use of Nanofluids in Radial Flow Cooling Systems Considering Temperature-Dependent Properties", Applied Thermal Engineering, Vol.26, 2209-2218, 2006.

[21] David R. Lide, "CRC Handbook of Chemistry and Physics", Former Director, Standard Reference Data, National Institute of Standards and Technology, 2005.

[22] Eiyad Abu-Nada, "Applications of Nanofluids for Heat Transfer Enhancement of Separated Flows Encountered in A Backward Facing Step",International Journal of Heat and Fluid Flow, Vol.29, pp.242-249, 2008.

[23] Shah R. K., "Thermal Entry Length Solutions for the Circular Tube and Parallel Plates", National Heat Mass Transfer Conference, Indian Institute of Technology, Bombay, Vol.1, 1975. 